\title{
Desarrollo regional y "Populorum Progressio"
}

\begin{abstract}
El desarrollo regional-en sentido econónico-nene que ser integrado en una política de desarrollo de las regiones-en sen. tido político.
\end{abstract}

Al poner sobre el tapete la cuestión del decarrollo regional es inevitable que surjan ciertas ilusiones en las regiones deprimidas. Algunos pueden pensar que ha llegado el momento de que se haga justicia a las regiones olvidadas. Pensendo en la justicia social aplicada a la localización del desarrollo, es inevitable que a un católico le venga a la mente el recuerdo de la Encíclica "POpulorum Progression, de Pablo VI. Sin embargo, la cuestión no es tan simple como pudiera aparecer a primera vista. Puede ser útil una reflexión sobre este problema para ayudar tanto a los responsables del desarrollo como a los habitantes de las regiones deprimidas. Los primeros tienen el peligro de encerrarse demasiado en criterios puramente económicos, con olvido de exigencias perentorias de la justicia, que, al no ser fácilmente cuantificables y mensurables dentro de un modelo económico de desarrollo, fácilmente quedan fuera de la consideración de los economistas. Los habitantes de las regiones subdesarrolladas pueden olvidar la inapelable lógica objetiva de las realidades económicas, que-nos guste o no nos guste-son como son y no admiten ilusiones precipitadas.

La doctrina del desarrollo regional es una aplicación del criterio espacial al desarrollo. Una aplicación de dicha doctrina que no produzca un desarrollo podrá ser "regional", pero no es "desarrollo" regional. Sólo se puede aplicar a áreas capaces de desarrollo de acuerdo con los medios disponibles, que son siempre !imitados y mucho más cuando no se ha alcanzado un alto nivel de riqueza nacional. Por otra parte, un desarrollo global que no repercuta en el desarrollo de las regiones deprimidas, además de no cumplir las exigencias de la justicia, carece de significación económica desde el punto de vista de dichas regiones. Se pasa de un desarrollo cero a un desarrollo cero, o, todo lo más, de 
un desarrollo "n" a un desarrollo "n"; es decir, se sigue igual que antes. Es necesario llegar a una síntesis de los criterios económicos y morales del desarrollo, y esto sólo se puede hacer en un nivel político, teniendo en cuenta criterios económicos, sociales y culturales. Es interesante estudiar la aportación que puede hacer la "Populorum Progressio" para la elaboración de una polímica de desarrollo regional.

\section{Desarrollo regional y justicia social.}

Una primera reflexión que se puede hacer es analizar los supuestos en que se mueven la teoría del desarrollo regional y la Encíclica "Populorum Progressio". El desarrollo regional es un concepto económico que se apoya en un concepto económico de región, distinto del concepto vulgar. Puede haber distintas mane. ras de entender el desarrollo regional, insistiendo más en el fenómeno de homogeneidad o en el de gravitación, pero todas coinciden en darle exclusivamente un sentido económico, sin atención a factores culturales o históricos.

La doctrina del desarrollo regional se produce en los países desarrollados. Se trata de corregir un desequilibrio originado fun. damentalmente por un fenómeno de saturación. Las zonas subdesarrolladas son sólo relativamente subdesarrolladas-su infraestructura económica y su nivel cultural son muy superiores a los de los países verdaderamente subdesarrollados-y constituyen una minoría en el conjunto. Son islotes de subdesarrollo en un conjunto altamente desarrollado. Los medios materiales y humanos que pueden ponerse al servicio del desarrollo son muy cuantiosos. La necesidad del desarrollo regional surge más del excesivo desarrollo de las zonas de alta concentración industrial y urbana, que de la relativa pobreza de las zonas subdesarrolladas. La excesiva concentración produce un descenso en la calidad de la vida y un aumento considerable en los costes sociales, que se trata de remediar extendiéndose a los espacios libres. En algunas ocasiones, el desarrollo regional trata de coordinar el ulterior desarrollo en zonas amplias ya desarrolladas.

El mimetismo propio de los países subdesarrollados intenta transplantar esta técnica a un ámbito de condiciones completamente distintas. El subdesarrollo domina en el país. La infraestructura es muy deficiente en el conjunto nacional. El hivel cultural, técnico y organizativo es muy bajo. Se requieren unas inversiones muy considerables y una riqueza humana que superan con mucho las propias posibilidades. Esta es la razón de que algunas naciones prefieran concentrar sus esfuerzos en objetivos muy limitados.

Existen algunas naciones de tipo medio-en el límite entre el desarrollo y el subdesarrollo-con zonas que empiezan a experi- 
mentar los inconvenientes de la saturación industrial y amplias zonas subdesarrolladas; dotadas de un fuerte dinamismo económico y con recursos que- $\sin$ ser tan considerables como los de las naciones claramente desarrolladas - no son nada despreciables. España es un ejemplo de este tipo medio. El desarrollo regional es necesario por razones sociales y económicas, pero requiere una planificación y una ejecución muy cuidadosa, con una acertada selección de objetivos y evitando tanto el derroche como la excesiva escasez o la inconstancia en las inversiones seleccionadas.

La Encíclica "Populorum Progressio" se mueve en supuestos completamente distintos. Se enfrenta con la injusticia que supone el contraste entre países altamente desarrollados y otros sumidos en la pobreza y el subdesarrollo. No son zonas sometidas a una jurisdicción común. La ausencia de unidad política se traduce en una gran diversidad de políticas económicas, fiscales, sociales. El comercio tropieza con grandes obstáculos-barreras aduaneras, monetarias, etc.- Los países subdesarrollados necesitan un crecimiento rápido de la economía nacional, porque parten de cotas muy bajas. Carecen de infraestructuras, de capital, de tecnología, de organización. El nivel cultural es bajo; la estructura social, arcaica; no existe la mano de obra especializada. Incluso se podría decir que hay una oposición entre el "desarrollo regional" y el "desarrollo de los pueblos". Esta afirmación no se encuentra en la "Populorum Progressio", pero se puede considerar que la sugiere indirectamente. En la segunda parte, cuando trata de justicia social en las relaciones comerciales, después de propugnar un trato de favor a los productos de los países subdesarrollados, afirma que eso es lo que hacen las naciones desarrolladas dentro de sus fronteras o en el interiol de un mercado común: "Así sucede que a menudo sostienen su agricultura a costa de sacrificios impuestos a los sectores económicos más favorecidos. Así también, para favorecer las relaciones comerciales que se desenvuelven entre ellos, particularmente en el interior de un mercado común, su política financiera. fiscal y social se esfuerza por procurar a industrias concurrentes de prosperidad desigual, oportunidades semejantes" (1). No se puede aplicar el principio del libre cambio a las naciones subdesarrolladas, "no estaría bien usar aquí dos pesos y dos medidas. Lo que vale en economía nacional, lo que se admite entre paises desarrollados, vale también en las relaciones comerciales entre países ricos y países pobres" (2).

Una búsqueda de espacios libres dentro de los mismos países desarrollados, para continuar el desarrollo, con olvido de los sub. desarrollados, iría contra el espíritu de la "Populorum Progressio". Sería exagerado encontrar una oposición radical entre el «desarro-

(1) PP 60. La numeración es de la edición de la BAC ("Ocho Grandes Mensajes", Madrid, 1972).

(2) PP 61. 
Ilo regional" y el "desarrollo de los pueblos", pero no cabe duda de que es necesario un toque de atención sobre la responsabilidad de los países desarrollados en la búsqueda de un justo equilibrio entre ambos desarrollos.

\section{El desarrollo de las regiones.}

El concepto de región que utiliza la teoría del desarrollo regional es puramente económico. Es legítimo simplificar los conceptos para poderlos utilizar en un modelo operativo, pero con tal de que se sea consciente de que se están manejando aspectos parciales de la realidad. Metodológicamente no hay inconveniente en distinguir los aspectos económicos, sociales, culturales y políticos de la vida social, pero en la realidad no son separables. No se puede actuar en uno de esos aspectos sin que se produzcan consecuenclas importantes en los otros. Hay un concepto de región mucho rás rico, que incluye factores culturales e históricos y que responde a una realidad social que no puede ser olvidada. Aunque la Encíclica "Populorum Progressio" no se refiere directamente al problema regional, establece unos principios que pueden ser aplicables a éste.

\section{Primer principio: Desarrollo humano.}

«El desarrollo no se reduce al simple crecimiento económico. Para ser auténtico debe ser integral, es decir, promover a todos los hombres y a todo el hombre. Con gran exactitud ha subrayado un eminente experto: Nosotros no aceptamos la separación de la economía de lo humano, el desarrollo de las civilizaciones en que está inscrito. Lo que cuenta para nosotros es el hombre, cada hombre, cada agrupación de hombres, hasta la humanidad enteran (3).

El desarrollo humano no considera a los hombres como puros individuos, sino que tiene en cuenta su dimensión social. La conservación y enriquecimiento del patrimonio espiritual y cultural en que se ha educado forma parte de su desarrollo personal. Si se atendiera sólo al criterio de rentabilidad, no tendría sentido el esfuerzo para el desarrollo de muchas naciones pobres. Sería más rentable canalizar todos los recursos hacia las naciones ya desarrolladas y emigrar todos a dichas naciones.

\section{Segundo principio: Desarrollo obligatorio.}

"Por otra parte, este crecimiento no es facultativo. De la misma manera que la creación entera está ordenada a su Creador, la cria-

(3) PP 14. 
tura espiritual está obligada a orientar espontáneamente su vida hacia Dios, verdad primera y bien soberano. Resulta así que el crecimiento humano constituye como un resumen de nuestros deberes. Más aún, esta armonía de la naturaleza, enriquecida por el esfuerzo personal y responsable, está llamada a superarse a sí misma" (4).

Si el desarrollo humano, que incluye necesariamente el desarro. llo económico, es obligatorio, también será obligatorio poner los medios necesarios. De aquí puede surgir una dificultad contra el principio anterior. Un apego excesivo a las propias tradiciones y a las propias particularidades puede ser un freno al desarrollo. Cuando se parte de niveles bajos es necesario aunar y concentrar los esfuerzos en objetivos limitados que posibiliten el ulterior desarrollo. Si el desarrollo económico tiene que ser también humano, no por eso tiene que dejar de ser desarrollo.

\section{Tercer principio: Respeto a la verdatera escala de valores.}

"Este crecimiento personal y comunitario se vería comprometido si se alterase la verdadera escala de valores. Es legitimo el deseo de lo necesario y el trabajar para conseguirlo es un deber; el que no quiera trabajar que no coma. Pero la adquisición de los bienes temporales puede conducir a la codicia, al deseo de tener cada vez más y a la tentación de acrecentar el propio poder. La avaricia de las personas, de las familias y de las naciones puede apoderarse lo mismo de los más desprovistos que de los más ricos y suscitar en los unos y en los otros un materialismo sofocante" (5).

Los valores económicos son auténticos valores, pero no son valores supremos. El "homo oeconomicus" es una ficción, aunque lo económico es una auténtica dimensión del hombre. La verdadera actitud moral no consiste en elegir unos valores y rechazar otros, sino en asumir todos los valores auténticos. Puede haber conflictos de valores; deben resolverse de la mejor manera posible y para ello es necesaria una escala de valores-un orden de preferencia-que responda a una concepción humana de la vida social. Desde otro punto de vista, el económico, también es desacertado el ignorar los factores extraeconómicos. Se puede prescindir de ellos en la elaboración de un modelo teórico, pero no en su aplica. ción a la realidad económica. El aparente conflicto entre los dos primeros principios sólo puede ser solucionado satisfactoriamente aplicando una recta escala de valores.

La "Populorum Progressio" hace algunas aplicaciones de estos principios, que nosotros podemos aplicar también por analogía. Al tratar de la promoción cultural, como elemento del desarrollo, afirma: "Rico o pobre, cada país posee una civilización, recibida de

(4) $\mathrm{PP} 16$.

(5) $\mathrm{PP} 18$. 
sus mayores: instituciones exigidas por la vida terrena y manifestaciones superiores-artisticas, intelectuales y religiosas-de la vida del espíritu. Mientras que éstas contengan verdaderos valores humanos, sería un grave error sacrificarlas a aquellas otras. Un pueblo que lo permitiera, perdería con ello lo mejor de sí mismo y sacrificaría, para vivir, sus razones de vivir. La enseñanza de Cristo vale también para los pueblos: ¿De qué le sirve al hombre ganar todo el mundo si pierde su alma?" (6).

La promoción cultural, no obstante, no consiste en la fijación de unas formas anquilosadas. El desarrollo cultural lleva a una universalización e integración de las culturas. Toda cultura auténtica es una cultura abierta. La solidaridad con todos los hombres no puede faltar en un desarrollo auténticamente humano (7).

Un excesivo apego a la propia nación puede ser contrario al desarrollo humano (analógicamente podríamos decir lo mismo de la Región): "El nacionalismo aísla los pueblos en contra de lo que es su verdadero bien. Sería particularmente nocivo allí en donde la debilidad de las economias nacionales exige, por el contrario, la puesta en común de los esfuerzos, de los conocimientos y de los medios financieros, para realizar los programas de desarrollo e incrementar los intercambios comerciales y culturales" (8).

\section{Conclusión}

En la Encíclica "Populorum Progressio" se contienen unos principios, que, aunque se refieren a unos supuestos distintos de los del desarrollo regional, pueden ser aplicados a éste. El desarrollo regional tiene que ser integrado en una política de desarrollo de las regiones, tratando de evitar dos extremos: un criterio exclusivo de rentabilidad económica y un criterio exclusivamente político, con olvido de los condicionamientos económicos. El primer criterio llevado al límite nos llevaría a emigrar todos a Alemania, llevándonos todos nuestros recursos y dejar España para el turismo, adonde podríamos venir como turistas todos los veranos. El segundo tendría su mejor expresión en la creación de polos de desarrollo en todas las provincias y repartir buenamente los recursos disponibles entre todas ellas. A nadie se le ocurririan cosas tan disparatadas, pero el olvido del necesario equilibrio entre el criterio económico y el político, aun en menor escala, no dejaría de ser cualitativamente el mismo disparate $y$-desde un punto de vista moral-es inadmisible.

F. B.

(6) PP 40.

(7) Pp 43 .

(8) pp 62. 